\title{
O AGRONEGÓCIO NO CERRADO DO SUDESTE GOIANO: UMA LEITURA SOBRE CAMPO ALEGRE DE GOIÁS, CATALÃO E IPAMERI
}

\section{The agribusiness in the cerrado of southeastern Goiás: A reading of Campo Alegre de Goiás, Catalão and Ipameri}

\author{
Patricia Francisca Matos \\ Profa. Dra. do Curso de Geografia da FACIP-UFU \\ patriciafmatos@yahoo.com.br \\ Vera Lúcia Salazar Pessôa \\ verinha.salazar@hotmail.com
}

Profa. Dra. do Curso de Pós-Graduação em Geografia da UFG-Campus de Catalão

Artigo recebido em 03/02/2012 e aceito para publicação em 17/04/2012

RESUMO: A territorialização da agricultura moderna no Sudeste Goiano metamorfoseou o espaço agrário de cerca de dez municípios, em consequência das "novas lógicas" que se instalaram, marcadas pelo uso intenso da ciência e da tecnologia, pela especialização produtiva - principalmente a produção de grãos, voltados para agroindústria e para mercado externo, pela territorialização de agroindústrias, enfim, por novas formas de exploração da terra. Somam-se a isso, a concentração de terras, os efeitos ambientais e a substituição de produtores tradicionais, em muitos casos camponeses, por empresários rurais. Assim, a territorialização do agronegócio promoveu, no Sudeste Goiano, sobretudo nos municípios de Campo Alegre de Goiás, Catalão e Ipameri, novos usos do território pelas empresas rurais e pelas agroindústrias, criando novas territorialidades no campo e na cidade.

Palavras-chave: Cerrado. Modernização da agricultura. Agronegócio. Território. Sudeste Goiano.

ABSTRACT: The territorialization of modern agriculture in Southeast of Goiás transformed the agrarian space of many municipalities as results of the "new logics" that if they had installed, marked by the intense use of science and the technology, by specialization, particularly the production of grains, aimed at agribusiness and foreign markets, by territorialization of agribusinesses, at last, new forms of exploration of the land. Added to this, the concentration of the land, the environmental effect and the replacement of traditional producers, in many cases peasants, for agribusiness entrepreneurs. Thus, the territorialization of the agribusiness, promove in the Southeast of Goiás, especially in the municipalities Campo Alegre de Goiás, Catalão and Ipameri, new uses of the territory by rural enterprises and the agricultural industries, creating new territoriality in the field and in the city.

Keywords: Cerrado (Savannah). Modernization of agriculture. Agribusiness. Territory. Southeast of Goiás. 


\section{INTRODUÇÃO}

A agricultura moderna, entendida como a incursão cada vez mais intensa das inovações tecnológicas e das metamorfoses da relação capital x trabalho, tem se propagado no Brasil, notadamente no Cerrado, como um modelo que altera as condições econômicas, contribuindo para o aumento da produção agrícola do país. Os dados quantitativos e qualitativos da produção agrícola, como se essa produção pertencesse a todos, forjam uma falsa imagem das reais consequências que o agronegócio gera para os biomas, para os trabalhadores e para a sociedade de um modo geral. O uso de inovações tecnológicas, a produção em alta escala, a dependência de elementos externos à propriedade, a integração com a indústria, a circulação da produção em outros países, a mobilidade geográfica do capital produtivo e financeiro são elementos, entre outros, da agricultura dita moderna. $\mathrm{Na}$ lógica capitalista, ser moderno é estar dentro desse sistema produtivo, que é excludente e concentrador. Seguramente, as empresas rurais são a "vitrine" da agricultura moderna no Brasil.

$\mathrm{Na}$ implantação da agricultura moderna, os espaços prioritários para investimentos de capital no Cerrado foram as áreas de chapada, ou chapadões. Pela planura de seu relevo, as chapadas são ideais, principalmente para aquelas culturas nas quais se têm maior capacidade de mecanização, como a soja e o milho. As chapadas também são dotadas de excelentes recursos hídricos, que possibilitam a irrigação de culturas no período seco (de maio a setembro). Assim, os fatores físicos foram muito importantes para a expansão da fronteira agrícola, pois, ao se apropriar, o capital não tem interesse apenas na terra, mas também no que ela contém de outros recursos naturais (água, relevo, clima) que podem proporcionar maior agregação de valor à produção.

Até o início dos anos 1970, as chapadas eram consideradas áreas impróprias para a produção agrícola, devido às condições físico-químicas do solo. Sendo assim, eram utilizadas para a pecuária e para o extrativismo. Eram áreas pouco valorizadas, se comparadas com as chamadas "terras de cultura", que possuíam um valor maior, por serem, estas últimas, propícias ao plantio de lavouras.
Com a modernização agrícola, as áreas de chapada passaram a ser as terras mais valiosas do Cerrado (renda da terra diferencial II). A inserção dos conteúdos técnico-científicos transformou esses espaços em grandes produtores de monoculturas. Com isso, as chapadas tornaram-se territórios do e para o capital. Em muitos municípios, as chapadas constituem "ilhas" de modernização, com a presença de muitos conteúdos da ciência em todo o processo produtivo. Nesses espaços, constitui-se, de fato, a industrialização da agricultura, em que as propriedades, geralmente de tamanho muito grande (de 500 a $30.000 \mathrm{ha}$ ), em nada se parecem com as fazendas tradicionais, pois sua lógica de produção é inerente a uma indústria. Por isso, as denominações de "empresas rurais" e "empresários rurais" para seus proprietários. Estes são, comumente, moradores do meio urbano e não necessariamente residem em cidades próximas à propriedade. Assim, pode-se dizer que a terra tem um significado puramente comercial.

Neste início do século XXI, não somente os chapadões encontram-se capturados pelo capital. Outros espaços do Cerrado também são alvos da produção do agronegócio, que não necessariamente precisa ser totalmente mecanizada. É o caso, por exemplo, da cana-de-açúcar, que vem se espraiando para diversas áreas do Cerrado para atender a demanda do setor sucroalcooleiro, o qual também tem feito, dessa região, território para sua consolidação.

Além dos fatores físicos, há a influência dos fatores exógenos (ação do Estado e de empresas privadas) para efetivar a territorialização do capital nas atividades agrícolas do Sudeste Goiano. Inclui-se, dentre os elementos, a localização muito próxima, dos municípios, a importantes centros consumidores, como Goiânia (GO), Brasília (DF) e Uberlândia (MG). Além disso, o Sudeste Goiano é servido pela rodovia federal BR-050, uma importante via de circulação que liga Brasília a São Paulo. Essa rodovia possibilita a entrada de muitas empresas rurais nos municípios de Ipameri e de Campo Alegre de Goiás, facilitando, com isso, o processo produtivo.

Assim, com o objetivo de compreender a tecedura do agronegócio no Sudeste Goiano, sob o enfoque geográfico, a abordagem encontra-se estruturada em dois itens; além da introdução, das consi- 
derações finais e das referências. No primeiro item, apresenta-se uma discussão sobre os sujeitos do capital no processo de reestruturação produtiva do Sudeste Goiano; em seguida, os territórios formados nas chapadas de Campo Alegre de Goiás, Catalão e Ipameri.

\section{DO SUL PARA O CERRADO: OS SUJEITOS DO CAPITAL NO PROCESSO DE REESTRUTU- RAÇÃO PRODUTIVA DO SUDESTE GOIANO}

O espaço agrário do Sudeste Goiano, após os anos 1980, passou por uma reestruturação produtiva, ocasionada pela territorialização do capital nas atividades agrícolas. Em outros espaços do Cerrado goiano, como a região Sudoeste, esse processo ocorreu logo no início de 1970, em consequência da expansão da fronteira agrícola. $\mathrm{O}$ processo de modernização da agricultura no Sudeste Goiano ocorreu com a chegada de produtores vindos do Sudeste e do Sul do Brasil: uns, com pouca disponibilidade de capitais, tendo, como apoio, créditos e programas do governo; outros, com fartos recursos financeiros para iniciar a produção em larga escala nas áreas do Cerrado. Esses produtores venderam suas terras nos seus estados de origem e compraram no Cerrado, por preços muito mais acessíveis. Também houve casos em que pessoas, mesmo sem experiência com a "lida da terra", que laboravam com outras atividades, resolveram, ainda sim, apostar na produção agrícola.

Por certo, no Sudeste Goiano, a presença do Estado não foi muito forte, mesmo porque, na década de 1980, já se presenciava o desmonte das políticas agrícolas. Porém, isso não significa que o Estado não tenha tido um papel expressivo. Com maiores ou menores dimensões, os sulistas que migraram para essa região foram beneficiados por políticas do governo, como programas, créditos ou obras de infraestruturas. Entre essas, estão o PRODECER (Programa Nipo-Brasileiro de Desenvolvimento Agrícola da Região dos Cerrados), através do qual se desenvolveu o Projeto de Colonização Paineiras, nos municípios de Campo Alegre de Goiás e de Ipameri, e o PROÁLCOOL, que favoreceu a instalação de uma usina de beneficiamento de cana-de-açúcar no município de Ipameri.
Assim, a territorialização do capital no Sudeste Goiano é distinta em relação aos diferentes municípios. Um dos fatores de diferenciação é o apoio do Estado, com mais veemência em alguns municípios, que tiveram maior inserção de capital privado, comparativamente a outros. Outro elemento importante é que, na década de 1980, já havia pesquisas consolidadas, principalmente da EMBRAPA, para a produção de soja e de outras monoculturas no Cerrado. E ainda, a territorialização da agricultura moderna, nas áreas do Sudeste Goiano, ocorreu num período em que as inovações agronômicas, físicas, químicas e biológicas estavam a todo vapor em outros lugares do espaço agrário nacional, o que demonstra a capacidade das inovações tecnológicas, juntamente com a hegemonia do capital financeiro, na transformação da estrutura produtiva do Cerrado.

Esses fatores possibilitaram a inserção da agricultura moderna, especialmente nas áreas de chapada, transformando esses territórios de agricultura e pecuária tradicionais em territórios produtores de grãos para atender a demanda dos mercados interno e externo; portanto, transformando em territórios do agronegócio. Não apenas os cultivos foram substituídos, como também os produtores locais perderam espaço para produtores vindos de outras localidades, modificando-se, assim, as condições de uso do espaço, a partir do emaranhado de relações sociais urdidas por esses novos atores.

Não diferentemente de outras áreas de Goiás com agricultura moderna consolidada, no Sudeste Goiano, são encontrados poucos produtores, principalmente nas chapadas, que sejam, em sua origem, goianos. Estes não tiveram incentivos para investir; eram considerados incapazes de exercer uma agricultura moderna. Já os produtores do Sul e do Sudeste eram considerados experientes na atividade agrícola e, portanto, segundo a visão do governo, pessoas ideais para receber incentivos para investir no Cerrado.

No Sudeste Goiano, os sulistas foram personagens do capital, "convidados" a compor o "novo" cenário agrícola das áreas de chapada. Esses novos sujeitos metamorfosearam não apenas a paisagem, com seus cultivos, mas também a estrutura da produção, transformando as fazendas em empresas rurais, espaço autêntico símbolo do capital. As em- 
presas rurais adotam as modernas tecnologias para o processo de produção, estão inseridas na nova divisão do trabalho, contam com especialização e gestão produtiva, com planejamento de todas as etapas da produção, com controle organizacional, estratégico, operacional, gerencial e administrativo. Nos municípios do Sudeste Goiano, há desde as mais "simples" até as mais "sofisticadas" empresas agrícolas.

Cabe um esclarecimento, aqui, do que se consideram "simples" e "sofisticadas" empresas agrícolas. Especialmente nos municípios de Ipameri, Campo Alegre de Goiás e Catalão estão territorializadas empresas agrícolas que contam com um padrão tecnológico moderno em todas as etapas do processo produtivo.Trabalham com monoculturas diversificadas para garantir maior exploração da terra e do trabalho, têm certificação de qualidade e possuem todo um padrão organizacional para competir no mercado e auferir maiores lucros. As empresas simples produzem também sob aparatos tecnológicos, mas em menores proporções, com menores volumes de capital e, às vezes, com tamanho menor de propriedade.

O poder econômico e social que as tradicionais fazendas de gado tinham em Goiás, por volta da década de 1970, foi substituído, em muitos municípios, pelas empresas rurais. Assim como a posição social do fazendeiro foi substituída pela figura do empresário rural. Este é chamado de empresário rural e não de fazendeiro. Com uma nova organização produtiva e novas relações sociais de produção e trabalho, as empresas rurais se estabeleceram no Cerrado como símbolo de progresso e modernidade. Os territórios que antes eram considerados entraves, como as chapadas, tornaram-se, com o uso de tecnologias e de capital os territórios mais adequados, no Cerrado, para a ampliação e a reprodução do agronegócio.

Outra questão relevante na configuração interna das empresas rurais do Sudeste Goiano é o fato de serem constituídas por famílias. São denominadas como empresas rurais familiares, porque são controladas e administradas por membros da família: pais e filhos ou apenas os filhos, sobrinhos, netos, enfim, os membros da família.

Das empresas rurais pesquisadas, todas são familiares, ou seja, não foi encontrada nenhuma empresa que tivesse um proprietário único. Há casos em que o pai veio junto com os filhos para investir na agricultura e, atualmente, já não comanda mais os negócios, que são dirigidos pelos filhos, conforme menciona um empresário rural beneficiário do projeto PRODECER: "o pessoal do Sul é muito família nos negócios, há uma sequência natural dos negócios".

É importante que se estabeleça a diferença entre empresa rural familiar e agricultura familiar. A agricultura familiar é um termo que vem sendo alvo de embates teóricos, tanto na Geografia quanto na Economia e na Sociologia. Existem inúmeras definições, controvérsias e caracterizações. Em linhas gerais, por agricultura familiar, entende-se uma unidade que produz com o trabalho da família e, normalmente, não contrata mão-de-obra assalariada e não vende sua força de trabalho, tendo como base de sustento o que a família produz, vendendo ou não o excedente. Empresa rural familiar também é um termo complexo e de muitos desafios analíticos. Primeiramente, quando se fala em empresa, lembra-se logo de algo relacionado ao meio urbano; e quando se menciona o termo "familiar," pode-se confundi-lo com um negócio pequeno, gerido apenas pela família. Porém, nem sempre é assim. Empresas familiares, tanto localizadas no meio urbano quanto no rural, podem ser grandes ou pequenas. A característica fundamental é que os proprietários sejam membros da família

Desse modo, nas empresas rurais familiares, os proprietários são membros da família, administram o processo produtivo, unindo os fatores terra, trabalho, capital e tecnologia. Possuem trabalhadores assalariados permanentes e temporários, conforme a necessidade da produção. Para Mendonça (2004), as empresas rurais constroem uma nova organização espacial, assim como programam novas relações sociais de produção e trabalho.

No Sudeste Goiano, as empresas rurais estão territorializadas, essencialmente, nas áreas de chapada. No levantamento realizado, constatamos que as empresas rurais do Sudeste Goiano identificadas são, na maioria, voltadas para a produção de grãos, tendo como carro-chefe a soja, seguida do milho. Secundariamente, com o processo de irrigação, os empresários rurais investem em culturas de 
café, algodão ou trigo. Além da produção de grãos, existem empresas na área de reflorestamento (pinus e eucalipto), no setor da cana-de-açúcar e no de hortifrutigranjeiros (cebola, batata e tomate).

Conforme as atividades das empresas agrícolas, observamos que os novos sujeitos territorializaram novos cultivos e, portanto, houve a criação de novas territorialidades ligadas ao modelo modernizante. Essas novas territorialidades se consolidaram em função da desterritorialização do agricultor regional, dos seus métodos, cultivos, hábitos culturais e relações sociais, e de sua reterritorialização, em muitos casos, no espaço urbano, onde perdeu o poder de cultivar a terra. Para Santos (2006), a adição de capital no espaço leva à corrente migratória em dois sentidos: a expulsão dos sujeitos que não se adaptam aos níveis técnicos e de capital; e a inserção, nesse espaço, de atores dotados das novas capacidades exigidas para movimentar as inovações técnico-científicas, gerando, consequentemente, novos usos do território.

\section{OS TERRITÓRIOS FORMADOS NAS CHAPA- DAS DE CAMPO ALEGRE DE GOIÁS, CATA- LÃO E IPAMERI: ARENAS DO CAPITAL}

A territorialização da agricultura moderna, expressa por meio do agronegócio, seja do cultivo de soja, de cana-de-açúcar ou de eucalipto, modifica também as relações sociais de produção no campo: aumenta a produção e a produtividade, com a incursão de novas culturas, novos métodos e tecnologias, assim como provoca a exclusão, desse fenômeno, de muitos sujeitos (trabalhadores/produtores). A expansão do capitalismo no campo, a ampliação do capital, produz, exclui e degrada. Essas três palavras caracterizam o agronegócio de uma forma geral, seja no Cerrado Goiano, no Cerrado Mineiro ou em outro lugar no qual o agronegócio territorializou-se.

Mas, se há características semelhantes em todos os lugares de territorialização da agricultura moderna, principalmente a exclusão social e a degradação ambiental, há também especificidades, tanto na forma de incursão quanto de expansão. No Sudeste Goiano, as especificidades estão expressas nas políticas públicas do Estado, na força do capi- tal privado, nos aspectos físicos e nas rugosidades históricas. As políticas públicas foram consolidadas, de forma mais visível, nos municípios de Ipameri e Campo Alegre de Goiás, por meio da implantação do PRODECER. Além deste, foi implantado o PROÁLCOOL, instalando-se uma usina de cana-de-açúcar para produção de álcool - Lasa Lago Azul. Com os incentivos deste programa, o empresário investiu não apenas no beneficiamento, mas também na produção da cana-de-açúcar, o que resultou numa importante usina no estado de Goiás, uma das indústrias de maior destaque no município de Ipameri.

Além desses programas, o Estado atuou e ainda atua no Sudeste Goiano, por meio da implantação de infraestruturas, principalmente para possibilitar o fluxo da produção, como construção e manutenção de rodovias pavimentadas e não pavimentadas, estradas vicinais e pontes. Entre as rodovias construídas, estão a GO-020, que liga Pires do Rio à BR-050, cortando a chapada de Ipameri; a GO-506, com entroncamento na BR-050, que liga Catalão ao Distrito de Santo Antônio do Rio Verde (principal rodovia de acesso à chapada de Catalão); e a GO-301, pavimentada em 2006, que corta as áreas de chapada de Catalão.

Além da infraestrutura criada, é importante considerar os financiamentos disponibilizados pelo governo (no Banco do Brasil) para os empresários rurais, tanto para o custeio (financiar a aquisição de insumos, fertilizantes, sementes e produtos necessários para o processo produtivo), quanto para investimentos (ampliar, diversificar e modernizar a produção).

No âmbito estadual, recursos do Produzir também são destinados às agroindústrias. Trata-se de um programa do governo de Goiás que incentiva a implantação e a expansão de indústrias, através de financiamento e de redução no valor do ICMS mensal.

A força do capital privado também está materializada no Sudeste Goiano, sendo isso mais aparente em alguns municípios, através de empresas rurais, principalmente em relação às inovações técnico-científicas. Em algumas empresas, essas inovações representam a "vitrine" da modernidade do agronegócio. $\mathrm{O}$ oposto ainda ocorre em pequenas propriedades camponesas que, vivendo um tempo 
lento em relação ao tempo rápido das empresas rurais, utilizam técnicas "rudimentares" no processo produtivo, como o arado com tração animal para o preparo da terra, e a matraca para o plantio dos grãos. A falta de energia elétrica e de outros itens de infraestrutura, bem como de moradias dignas, também faz parte da paisagem de muitas propriedades. Esse contexto permite identificar as mudanças rápidas no território, em decorrência do processo de territorialização da agricultura moderna, por um lado, e os territórios que ainda permanecem em um tempo lento, por outro.

No Cerrado, as áreas de chapada tornaram-se palco de grandes investimentos do capital público e privado. Em virtude, principalmente, das potencialidades físicas, esses territórios foram escolhidos para a consolidação da agricultura moderna. No Sudeste Goiano, essa situação não foi distinta. O capital se territorializou de forma mais específica nas chapadas, também denominadas e conhecidas como chapadões. Foi justamente nos municípios com grandes extensões de áreas de relevo plano, ou suavemente ondulado, que a modernização da agricultura se efetivou, como é o caso de Campo Alegre de Goiás, Catalão e Ipameri. Por isso, nem todos os municípios tiveram esse processo consolidado, porque os elementos naturais (principalmente água e relevo) não contribuíram para a inserção desse modelo de agricultura. Esses elementos naturais, somados às inovações tecnológicas, viabilizaram a integração de alguns municípios do Sudeste Goiano ao sistema produtivo capitalista.

A influência do relevo nesse processo de modernização da agricultura é notada no Sudeste Goiano, por dois fatos. Primeiro: observando-se município por município, vê-se que o capital não se territorializou de forma homogênea, uma vez que se concentra, prioritariamente, nas chapadas, as quais, além da topografia plana, têm boa disponibilidade de água. Segundo: nas próprias chapadas, as partes de relevo onde as máquinas não conseguem penetrar são os lugares em que ainda resta um pouco de vegetação do Cerrado. Nas demais áreas, essa vegetação foi toda eliminada, cedendo lugar para as monoculturas. Tanto é assim que, em entrevistas, 90\% dos empresários rurais alegam que os fatores água e relevo foram decisivos para a escolha do município; $10 \%$ salientam que os elementos decisivos foram o relevo e o clima.

Os dados sobre uso da terra dos municípios de Campo Alegre de Goiás, Catalão e Ipameri (Tabela 1) evidenciam que a agricultura é mais explorada nas áreas de chapada, assim como é nelas que há maior concentração de pivôs, ou seja, de agricultura irrigada. Conforme os dados da tabela, observa-se que os recursos hídricos são mais explorados no processo de irrigação em Campo Alegre de Goiás, Catalão e Ipameri, que contam com 46,94, 36,56 e $34,59 \mathrm{~km}^{2}$ de áreas irrigadas, respectivamente. Em relação à agricultura, o município de Catalão destaca-se com $\left(691,49 \mathrm{~km}^{2}\right)$, seguido de Ipameri $(537,09$ $\mathrm{km}^{2}$ ) e Campo Alegre de Goiás $\left(441,08 \mathrm{~km}^{2}\right)$. Porém, considerando-se o tamanho proporcional dos municípios, observa-se que a exploração maior ocorre em Campo Alegre de Goiás, com 18\% de sua área ocupada pela agricultura. Em Catalão, a área ocupada pela agricultura é de 17\%; em Ipameri, de 13\%. Em todos os municípios apresentados na tabela 1 , as áreas de pastagem ainda lideram a ocupação e o uso da terra.

Em Campo Alegre de Goiás, Catalão e Ipameri, as áreas de chapada se configuraram em "ilhas de modernidade," devido às densidades técnicas presentes no processo produtivo e, portanto, tornaram-se territórios de ação/atuação de empresas rurais e agroindústrias; enfim, território de reprodução do capital. É também nessas áreas que fica evidente a destruição do Cerrado em relação às outras áreas do município. 
Tabela 1- Campo Alegre de Goiás, Catalão, Ipameri e Orizona : uso da terra em 2010

\begin{tabular}{|c|c|c|c|c|}
\hline \multirow{3}{*}{ Uso da terra } & \multicolumn{4}{|c|}{ Municípios } \\
\hline & \multicolumn{4}{|c|}{ Área km² } \\
\hline & $\begin{array}{c}\text { Campo Alegre } \\
\text { de Goiás }\end{array}$ & Catalão & Ipameri & Orizona \\
\hline Pastagem & 814,44 & $1.223,95$ & $1.724,97$ & 789,07 \\
\hline Cerrado Ralo & 266,98 & 691,53 & 505,10 & 218,05 \\
\hline Mata ciliar & 268,32 & 347,05 & 604,17 & 391,39 \\
\hline Cerrado & 343,42 & 374,75 & 597,19 & 184,02 \\
\hline Agricultura & 441,08 & 691,49 & 537,09 & 272,81 \\
\hline Solo exposto & 240,31 & 202,03 & 342,71 & 100,14 \\
\hline Represa & 32,50 & 156,08 & - & - \\
\hline Área urbana & 2,93 & 27,33 & 9,67 & 3,86 \\
\hline Pivô & 46,94 & 36,56 & 34,59 & 7,07 \\
\hline
\end{tabular}

Fonte: Imagens de Satélite LANDSAT 5TM, 2010.

Org.: MATOS, P, F., 2010.

Desse modo, consideram-se as áreas de chapada como arena do capital, por elas terem sido território escolhido pelo capital, que delas se apropriou e fez uso para efetivar sua dinâmica de acumulação e reprodução. Com isso, esses territórios ganharam novos significados econômicos, devido a ações materiais e imateriais ali territorializadas. Com a modernização da agricultura, essa parte do Cerrado ilustra um novo tempo: um tempo impregnado pela difusão cada vez mais veloz das inovações técnico-científicas. A presença, no território, de signos materiais e imateriais integrados à lógica do sistema capitalista estabelece uma nova lógica da divisão do trabalho, da especialização do espaço e da produção, e configura, assim, novas territorialidades.

Observando-se as unidades produtivas das áreas de chapada, percebe-se um "rural modernizado" e "industrializado"; quase todas as propriedades estão inseridas na dinâmica de produção e organização do período tecnológico. "O campo modernizado é o lugar das novas monoculturas e das novas associações produtivas, ancoradas na ciência e na técnica e dependentes de uma informação sem a qual nenhum trabalho rentável é possível," (SANTOS, 2006, p. 243). As propriedades configuram-se em espaços impregnados de conteúdo técnico-científico-informacional, materializado nos meios de produção, nas relações sociais, na comercialização, no controle da produção e na própria paisagem.

Quando se chega às áreas de chapada, à primeira vista, a aparência é homogênea e monótona. Mas, logo se vê a dinâmica e a movimentação da produção, e as relações de produção estabelecidas por produtores e empresas do agronegócio. O processo produtivo é marcado por mecanização, pulverização das lavouras, presença de agrônomos monitorando as plantações, utilização da previsão do tempo, da cotação da soja, enfim, naquele espaço, está inserido tudo que a agricultura científica globalizada requer.

\section{[...] cada gesto e cada resultado deve ser} previsto de modo a assegurar a maior produtividade e a maior rentabilidade possivel. Plantas e animais já não são herdados das gerações anteriores, mas só há criaturas da biotecnologia; as técnicas, a serviço da produção, da armazenagem, do transporte, da transformação dos produtos e da sua distribuição, respondem ao modelo mundial e são calcadas em objetivos pragmáticos, tanto mais provavelmente alcançados, quanto mais claro for o cálculo na sua escolha e na sua implantação. (SANTOS, 2006, p. 304).

As relações de poder estão materializadas nas empresas rurais, pelos meios de produção, influenciando na maior ou menor competitividade no mercado; e também no poder econômico e/ou político que exercem nos municípios. As empresas fornecedoras de insumos e sementes controlam es- 
ses territórios por meio das formas de pagamento, do financiamento da produção e/ou do monitoramento das culturas. As multinacionais que compram grãos têm o controle do mercado e, por vezes, também controlam o fornecimento de sementes, agrotóxicos e fertilizantes. Tais empresas demonstram o seu poder na área de produção, mostrando que aquele território tem sua biotecnologia.

Nas chapadas do município de Campo Alegre de Goiás, Catalão e Ipameri, normalmente, não há demarcação material, cerca separando uma propriedade da outra. O que as divide, geralmente, é uma estrada. As chapadas possuem muitas estradas, para facilitar a circulação de veículos que fazem o monitoramento das lavouras e o escoamento da produção. Nas propriedades, exceto nas sedes, teoricamente, o acesso é livre, porque não há porteiras ou cercas impedindo a circulação. No entanto, há receio, por parte de pessoas estranhas àquele território, de transitarem nas propriedades, por saberem que, mesmo não existindo impedimentos materiais, a circulação é proibida. Já as sedes das empresas rurais, onde ficam os silos, os galpões de máquinas, as casas, os alojamentos, enfim, toda a estrutura produtiva, são delimitadas, geralmente, por cercas vivas. Para entrar, é preciso solicitar a permissão, uma vez que há uma portaria, com seguranças monitorando a entrada e a saída de pessoas e veículos. As cercas vivas das empresas são, na maioria, de eucaliptos, que também servem como barreira contra o vento, ou seja, funcionam como quebra-vento, haja vista que a retirada da vegetação natural torna a propagação dos ventos mais intensa.

Assim, as relações de poder no processo de territorialização do capital no espaço agrário são exercidas pelo sistema financeiro, pelo Estado, pelas indústrias, cooperativas, comerciantes, empresários rurais, enfim, por diferentes atores que, de várias formas, participam do processo de produção. Esses agentes podem ou não estar visíveis no território. Os bancos, por exemplo, não estão visíveis, mas controlam e dominam territórios, por meio de financiamentos. De uma forma geral, não são todos os elementos de influência no processo produtivo agrícola que estão materializados na paisagem do município ou da região. Em termos de distância, podem estar longe, mas, possuem o domínio.

A quantidade da produção também caracteriza as relações de poder nas áreas de chapada. Alguns empresários rurais se destacam pela alta produção nas chapadas de Catalão, de Campo Alegre de Goiás e de Ipameri. Os maiores produtores têm notoriedade tanto entre os demais empresários rurais, como no comércio de equipamentos agrícolas, de insumos e de sementes. Pelos dados da produção, também é possível mensurar as relações de poder e de uso do território pelo agronegócio nos municípios.

O município de Catalão é o maior produtor de soja do Sudeste Goiano, atualmente. No ano de 1975, a produção de soja era inexpressiva. A partir de 1980, essa cultura registra aumento expressivo, tornando-se o principal cultivo do município. Em um período de dez anos (1980 a 1990), a área plantada cresceu mais de dez vezes, passando de 723 hectares para 22.000 hectares. Nos períodos posteriores, o cultivo da soja aumentou de forma abrupta, chegando, em 2008, à maior área plantada e à maior produção de todos os tempos: 76.000 hectares de área plantada e uma produção de 243.200 toneladas. A produção de milho também registrou enorme crescimento após 1980 (Tabela 2). Diferentemente da soja, nos anos precedentes, havia uma produção significativa, pois o milho é um cultivo tradicional no Cerrado. Porém, com a modernização agrícola, o milho se constituiu uma das principais monoculturas mecanizadas.

Em Ipameri, a soja começou a expandir-se após 1980, obtendo crescimento em todos os anos. O milho também conseguiu crescimento significativo em todo o período analisado, principalmente após os anos de 1990 (Tabela 3). No município de Campo Alegre de Goiás, observando-se os dados apresentados na tabela 4, verifica-se o elevado crescimento da área de plantação de soja e da produção obtida a cada safra. Em 2008, a soja produzida em Campo Alegre de Goiás teve participação de 2,6\% na produção estadual. O milho, segunda cultura de destaque no município, obteve crescimentos significativos de $1990 \mathrm{em}$ diante, porém, com oscilações de área plantada em alguns anos analisados. 
Tabela 2- Catalão (GO): área plantada e produção de soja e milho, 1975 - 2008 (anos selecionados)

\begin{tabular}{l|llll}
\hline \multirow{2}{*}{ Ano } & \multicolumn{3}{|c}{ Soja } & Milho \\
\cline { 2 - 5 } 1975 & Área (ha) & Produção (t) & Área (ha) & Produção (t) \\
1980 & 5 & 1 & 4.757 & 6.502 \\
1990 & 723 & 681 & 3.564 & 5.272 \\
1995 & 22.000 & 26.400 & 3.500 & 9.900 \\
2000 & 37.000 & 55.500 & 6.100 & 25.200 \\
2005 & 48.000 & 129.000 & 11.900 & 72.480 \\
2008 & 75.000 & 238.500 & 11.000 & 77.000 \\
\hline
\end{tabular}

Fonte: IBGE - Censos Agropecuários (GO) de1975 e 1980 e Produção Municipal, de 1990 a 2007.

A produção de arroz, conforme mostra a figura 1, oscilou em área plantada e produção, nos anos analisados. Porém, a menor safra foi a de 2008. De 1975 a 1980, houve maior crescimento de área plantada nos municípios de Campo Alegre de Goiás e de Ipameri. Esse aumento ocorreu em virtude dos migrantes sulistas utilizarem o arroz para "abrir a área", isto é, o arroz era cultivado no intuito de se corrigir a acidez dos solos, prática comum no Cerrado, na expansão da fronteira agrícola.

No município de Campo Alegre, a situação do cultivo de arroz não foi diferente daquela dos outros municípios pesquisados, ou seja, ocorreu redução da área plantada, correndo-se o risco de, futura-

Tabela 3-Ipameri (GO): área plantada e produção de soja e milho, 1975-2008 (anos selecionados)

\begin{tabular}{l|llll}
\hline \multirow{2}{*}{ Ano } & \multicolumn{3}{|c}{ Soja } & Milho \\
\cline { 2 - 5 } 1975 & Área (ha) & Produção (t) & Área (ha) & Produção (t) \\
1980 & - & - & 3.109 & 3.860 \\
1990 & 9 & 14 & 3.403 & 4.345 \\
1995 & 25.000 & 30.000 & 3.500 & 4.900 \\
2000 & 28.000 & 47.600 & 12.000 & 46.800 \\
2005 & 43.000 & 103.000 & 14.800 & 76.050 \\
2008 & 66.000 & 207.900 & 12.000 & 84.000 \\
& 67.000 & 214.400 & 18.800 & 123.600 \\
\hline
\end{tabular}

Fonte: IBGE - Censos Agropecuários (GO) de 1975 e de 1980 e Produção Municipal, de 1990 a 2007.

Org.: MATOS, P. F., 2010.

Tabela 4- Campo Alegre de Goiás: evolução da área plantada e da produção de soja e milho, 1975 - 2008

(anos selecionados)

\begin{tabular}{c|llll}
\hline \multirow{2}{*}{ Ano } & \multicolumn{3}{|c}{ Soja } & Milho \\
\cline { 2 - 5 } & Área (ha) & Produção (t) & Área (ha) & Produção (t) \\
1975 & 24 & 4 & 1.762 & 1.350 \\
1980 & 7 & 38 & 1.314 & 1.255 \\
1990 & 19.000 & 28.500 & 8.200 & 12.480 \\
1995 & 30.000 & 45.000 & 8.250 & 43.800 \\
2000 & 35.500 & 85.000 & 7.860 & 32.448 \\
2005 & 55.000 & 176.000 & 5.500 & 38.500 \\
2008 & 57.000 & 177.840 & 8.500 & 61.200 \\
\hline
\end{tabular}

Fonte: IBGE - Censos Agropecuários (GO) 1975 e 1980 e Produção Municipal de 1990 a 2007.

Org.: MATOS, P. F., 2010. 
mente, essa cultura ser extinta das práticas agrícolas desse município. A produção de feijão em Catalão, em Campo Alegre de Goiás e em Ipameri também apresenta oscilações na área plantada e na quantidade produzida (Figura 2). Esse cultivo também é feito pe- las empresas rurais na prática de rotação das culturas irrigadas que, normalmente, varia entre o sorgo e o trigo, dependendo do que está com o preço mais alto no mercado.

Figura 1 - Catalão, Campo Alegre de Goiás e Ipameri (GO): produção de arroz,

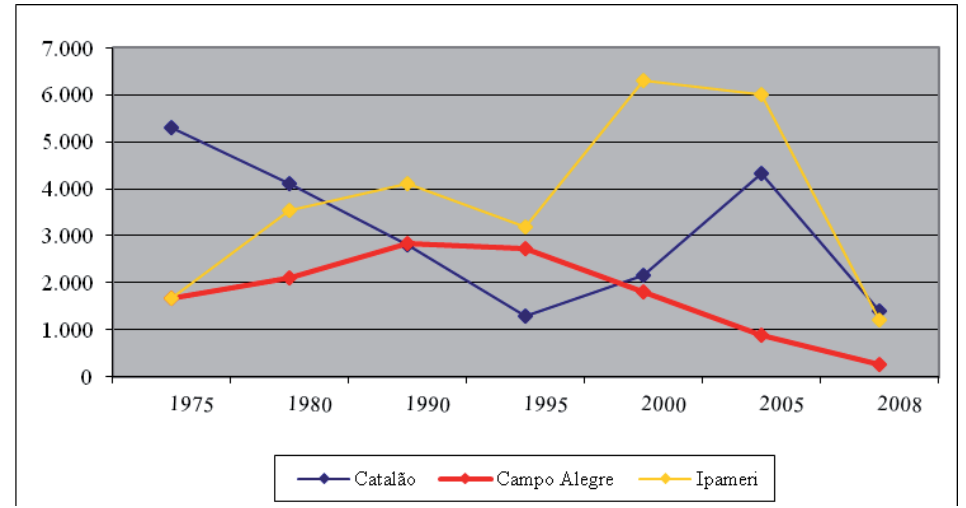

Fonte: IBGE - Censos Agropecuários (GO), de 1975 e de1980 e Produção Municipal, de 1990 a 2008.

Org.: MATOS, P. F., 2010.

Diante dos dados da produção de soja, milho, arroz e feijão, observa-se que a territorialização do capital no espaço agrário, num curto espaço de tempo, metamorfoseou a estrutura produtiva, de forma que culturas de grãos para as indústrias ou para o mercado externo ganharam espaço em Catalão, em Campo Alegre de Goiás e em Ipameri. Todos esses municípios seguiram a tendência nacional de cresci- mento da soja e do milho, e de diminuição do arroz e do feijão; sendo estes últimos, alimentos essenciais para os brasileiros. Porém, é importante considerar que o consumo de alimentos industrializados derivados de soja, por exemplo, aumentou, contribuindo, dessa forma, para o aumento da demanda dessa oleaginosa.

Figura 2 - Catalão, Campo Alegre de Goiás e Ipameri (GO): produção (t) de feijão, 1975 2008 (anos selecionados).

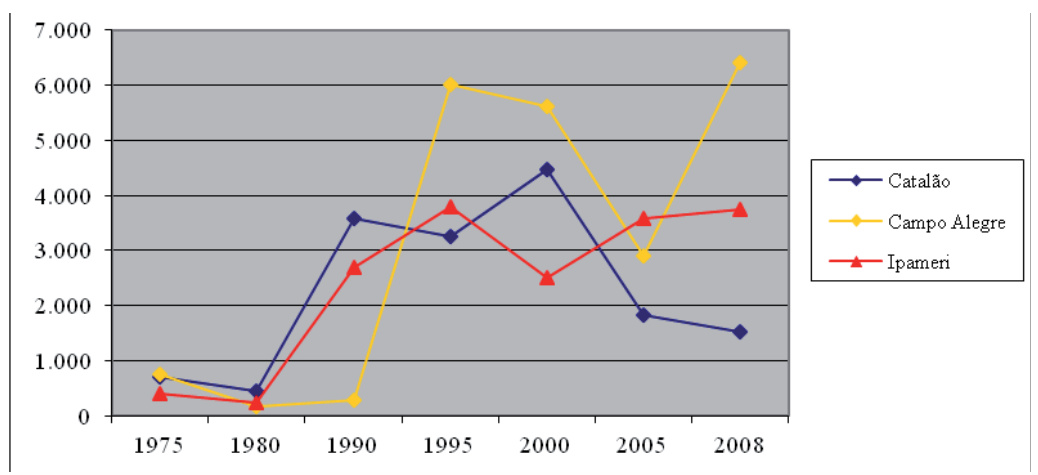

Fonte: IBGE - Censos Agropecuários (GO), de 1975 e de 1980 e Produção Municipal de 1990 a 2007. Org.: MATOS, P. F., 2010. 


\section{CONSIDERAÇÕES FINAIS}

As áreas de Cerrado, desde a década de 1970, tornaram-se palco de transformações espaciais, sociais, econômicas, ambientais, urbanas e culturais decorrentes da reestruturação produtiva, devido à modernização da agricultura, via expansão do agronegócio. Desde esse período, o agronegócio vem conquistando "fatias" do território do Cerrado, com a consolidação de empresas rurais, agroindústrias, principalmente ligadas ao setor grão-carne e traddings, entre outras empresas ligadas ao ramo do agronegócio, modificando os usos do território, criando novas paisagens e novas formas de produção, pautadas na inserção do meio técnico-científico-informacional.

A constituição do meio técnico-científico-informacional nas áreas de Cerrado promoveu a densificação de fixos e fluxos, gerando maior fluidez (quantitativa e qualitativa) na circulação de capital, pessoas, mercadorias e informação. Com isso, uma série de novas possibilidades materiais e sociais de uso do território foi estabelecida. As inúmeras agroindústrias instaladas nos estados do Mato Grosso, do Mato Grosso do Sul e de Goiás são exemplos dos novos usos do território. O movimento da produção agrícola moderna necessita de determinados usos do território, e os impõe, diferentes dos impostos pela agricultura tradicional. São agroindústrias processadoras de alimentos, crescimento de cidades do agronegócio, inserção de multinacionais (ADM, Cargill, Bunge etc.), formação de novos corredores logísti$\cos$, entre outros fatores que, em conjunto, estabelecem as redes e as tipologias do uso do território.

No início do processo de consolidação da agricultura moderna no Cerrado, foram fundamentais as ações governamentais de investir em pesquisas para obtenção de tecnologia, principalmente as inovações físico-químicas para fazer o melhoramento dos solos, a fim de adequá-los às novas demandas do capital, que eram representadas pelas commodities. Nesse sentido, a EMBRAPA e empresas privadas tiveram uma atuação preponderante no processo de colocar as terras do Cerrado para produzir culturas alheias a seu histórico produtivo, como a soja e o trigo, e para aumentar e modificar a produção de culturas tradicionais, como o milho.

A reestruturação produtiva nas áreas de Cerrado faz parte de um processo que ocorreu em nível nacional, visando produzir cultivos articulados com os mercados nacional e internacional. Esse processo iniciou-se com a produção de soja e, posteriormente, vieram outros cultivos, como algodão, café, trigo e milho. Esses cultivos, de forma veloz, foram ocupando o espaço das lavouras de arroz e de feijão. Este último tornou-se uma opção para as empresas rurais no processo de irrigação, não sofrendo, por causa disso, declínio da produção, como foi o declínio desastroso da produção de arroz. Porém, a área ocupada pelo feijão é muita pequena, se comparada à ocupada pela soja e pelo milho. Outra cultura que se incorporou à cadeia produtiva das áreas do Cerrado foi a cana-de-açúcar. Apesar de ser uma cultura que já estava presente no Cerrado, com a implantação do PROÁCOOL, no final de 1980, ela recrudesceu e seus índices de produção aumentaram de forma significativa. Porém, foi no inicio do século XXI que o Cerrado tornou-se, de fato, território prioritário para a expansão dos canaviais, em função do projeto dos biocombustíveis, que colocou a cana como a principal opção para a produção de álcool.

Constata-se que a modernização do campo, com todas as atividades a ela ligadas, é responsável também pelo avanço econômico do estado de Goiás. Todavia, o que se têm mostrado em muitas pesquisas é a insustentabilidade social e ambiental desse modelo. Embora os efeitos sócio-ambientais sejam mais evidentes nas áreas onde está materializada a agricultura moderna, toda a sociedade sofre, de forma direta ou indireta, esses efeitos. Em relação aos efeitos ambientais, por exemplo, a destruição do Cerrado contribui para as mudanças climáticas no Brasil e no mundo. A pouca produção do arroz e do feijão nas áreas de Cerrado, em detrimento da soja, do milho e da cana, tem contribuído para que esses grãos tenham o seu preço elevado, atingindo a população de todas as classes sociais.

Isto posto, cabe ressaltar que, nas áreas do Cerrado incorporadas pelo agronegócio, há uma lógica modernizadora que articula a escala local com 
a internacional, organizando o espaço conforme imposições do mercado, essencialmente de corporações multinacionais. Na lógica modernizadora, as densidades técnicas difundidas em função do agronegócio contribuem para a modernização do território, portanto, para o aumento dos fixos e fluxos.

Sob o enfoque da modernização do território, que compreende a modernização da agricultura, entende-se que não ocorre apenas a modernização das técnicas de produção, e sim de todo o processo de produção e circulação. Na década de 1970, quando se iniciou a territorialização da agricultura moderna empresarial no espaço agrário do Cerrado, não havia densidade técnica suficiente para o processo produtivo, mas o Estado foi equipando o território, para viabilizar o processo produtivo, com energia elétrica, rodovias pavimentadas e aeroportos, entre outros fixos para viabilizar os fluxos.

O conceito de território foi priorizado neste trabalho, a fim de se compreender a territorialização da agricultura moderna na região Sudeste de Goiás, considerando-se que esta região foi se transformando em múltiplos territórios, entre eles, os do agronegócio que, para reprodução do capital, estabelecem novos usos do território, por meio de inovações tecnológicas e à custa de danos ambientais e sociais graves. Esses novos usos do território ocorreram principalmente nas áreas de chapada, denominadas no decorrer do trabalho como arena do capital. Principalmente nesse espaço, ocorreu a territorialização das empresas rurais, com o uso das mais modernas tecnologias no sistema produtivo. São territórios de produção que se diferenciam das demais áreas dos municípios, em relação à exploração dos recursos naturais, à concentração de terras e à precarização do trabalho. As empresas rurais têm como característica a produção em alta escala e, para isso, precisam de muita terra, o que leva, então, à concentração de terras. Nos municípios de Campo Alegre de Goiás, Catalão e Ipameri, impressiona o tamanho das empresas rurais nas áreas de chapada, que têm desde 1.000 até 30.000 hectares. Situação diferente encontrou-se no município de Orizona, cujas empresas rurais não ultrapassam 1.500 hectares. Outro fato que impressiona é a exploração dos recursos naturais, principalmente os recursos hídricos para irrigação: rios, ribeirões, córregos e ve- redas. Um exemplo constatado foi, em uma empresa rural localizada na chapada de Catalão, a construção de um canal no rio São Bento (um importante rio da região) para irrigar lavouras. Para dificultar o acesso a essa área irrigada, foram colocadas armadilhas na estrada que leva à lavoura, de forma que, se passar algum veículo no local, ele tem os pneus estourados.

No decorrer da pesquisa, também foram observadas as relações de trabalho estabelecidas nos territórios do agronegócio, especificamente nas empresas rurais. As características mais comuns da ofensiva do capital sobre o trabalho nesse sistema de produção são a diminuição da quantidade de trabalhadores, em função da mecanização, a exigência de mão de obra qualificada, a terceirização, e a precarização, em geral, das condições de trabalho.

Outro aspecto a ser considerado são as relações de poder, o controle que os empresários rurais passam a ter nos território das chapadas, principalmente com a produção e as técnicas agrícolas, em relação às outras áreas dos municípios. Somam-se a isso, as relações de poder estabelecidas na política e, em alguns casos, na identidade cultural da cidade, por exemplo, com realização de festas típicas de suas regiões, como o "Baile do Gaúcho".

É salutar relembrar que, no Sudeste Goiano, existem diferentes ritmos de modernização nas áreas de chapada, em função das distintas forças de poder que atuam sobre esses territórios, como também das forças de resistências, que podem interferir na organização produtiva desses territórios. Por isso, considera-se que a modernização da agricultura metamorfoseou muitos espaços do Sudeste Goiano em territórios do agronegócio, porém, não é apenas essa atividade que domina e faz uso do território.

\section{REFERÊNCIAS}

ASSOCIAÇÃO BRASILEIRA DE NORMAS TÉCNICAS. NBR 6023: informação e documentação: referências: elaboração. Rio de Janeiro, 2002.

. NBR 14724: informação e documentação: trabalhos acadêmicos: apresentação. Rio de Janeiro, 2011. 
ARRUDA, Z.A.de. Onde está o agro deste negócio: transformações socioespaciais em Mato Grosso decorrentes do agronegócio. 2007. 253f. Tese (Doutorado em Geografia) -Instituto de Geociências- UNICAMP, Campinas, 2007.

BRUM, A. J. Modernização da agricultura: trigo e soja. Petrópolis: Vozes, 1988.

ELIAS, D. Globalização e agricultura. São Paulo: EDUSP, 2003.

FERNANDES, B. M . O novo nome é agribusines. Publicações Nera, 2004. Disponível em: http:// www4.fct.unesp.br/nera/publicacoes/onomeeagribusiness.pdf. Acesso em: 15 jun. 2009.

GRAZIANO DA SILVA, J. A modernização doloro$s a$ : estrutura agrária, fronteira agrícola e trabalhadores rurais no Brasil. Rio de Janeiro: Zahar, 1981.

INOCÊNCIO, M.E. O PRODECER e as tramas do poder na territorialização do capital no Cerrado. 2010. 278 f. Tese (Doutorado em Geografia)-Instituto de Estudo Sócio-Ambientais, UFG, Goiânia, 2010.

HAESBAERT, R Des-territorialização e identidade: a rede "gaúcha" no nordeste. Niterói: EDUFF, 1997.

IBGE. Censos Agropecuários. Disponível em: http:// www.ibge.gov.br, 2004. Acesso em: 10 dez. 2008.

Censo Agropecuário de Goiás, 1980. Disponível em: http://_www.ibge.gov.br, 2009. Acesso em: 30 maio. 2009.

IBGE. Censo Agropecuário de Goiás, 1985. Disponível em: http://www.ibge.gov.br, 2009. Acesso em: 30 maio. 2009.
Produção Municipal de Goiás, 1990/2005. Disponível em: http://www.ibge.gov.br, 2009. Acesso em: 15 de maio. 2009.

IBGE Sidra. Disponível em: <http://www. ibge.gov.br/sidra>. Acesso em: 22 maio. 2009.

MENDONÇA, M. R. A urdidura espacial do capital e do trabalho no cerrado do Sudeste goiano. 2004. $448 \mathrm{f}$. Tese (Doutorado em Geografia) - Faculdade de Ciências e Tecnologia, UNESP, Presidente Prudente, 2004.

PESSÔA, V. L. Ação do Estado e as transformações agrárias no cerrado das zonas de Paracatu e alto Paranaíba-MG. 1988. 239f. Tese (Doutorado em Organização do Espaço)- Instituto de Geociências e Ciências Exatas, UNESP, Rio Claro, 1989.

RAFFESTIN, C. Por uma geografia do poder. Tradução de Maria Cecília França. São Paulo: Ática, 1993.

SANTOS, M,; SILVEIRA, M. L. O Brasil: território e sociedade no início do século XXI. 10 ed. São Paulo: Record, 2008.

SANTOS, M. Da totalidade ao lugar. São Paulo: Edusp, 2005.

A natureza do espaço: técnica e tempo, razão e emoção. 4.ed. São Paulo: HUCITEC, 2006.

. Metamorfoses do espaço habitado. 6 ed. São Paulo: HUCITEC, 2008. 